\title{
The intact rock strength of anisotropic rocks in the Pilbara: the use of field estimations, practical limitations of calibrations and statistical bias
}

\author{
A Maldonado The University of Western Australia, Australia \\ PM Dight Australian Centre for Geomechanics, The University of Western Australia, Australia \\ K Mercer 3rd Rock Consulting, Australia
}

\begin{abstract}
The uniaxial compressive strength (UCS) is an essential input parameter of the Hoek \& Brown failure criterion to represent the shear strength of rock masses, which is frequently used for slope stability analysis in the mining industry. This paper presents the use of the field estimated strength (FES) as a way to estimate the UCS, which is not a new idea but rather a regular practice applied by consultants and internal engineers within BHP Iron Ore for the last 20 years. However, the paper puts emphasis on the practical limitations related to the FES calibration by spot sampling, the bias effects caused by 'length-weighted' calculations due to the skewness distribution on FES and presents a logarithmic transformation on FES as a manner to test similarity of typical values. The paper concludes presenting typical values as defined by statistical similarity 'hypothesis testing' on FES data of the same stratigraphical rock units across different locations in the Pilbara.
\end{abstract}

Keywords: UCS, field estimated strength, length-weighted, skewness, hypothesis testing

\section{Introduction}

As presented in the literature of rock mechanics (Hoek 2000), the intact rock strength is determined by laboratory testing of diamond core specimen using uniaxial loading machine to measure the maximum load reached by the intact rock at failure, which represents the uniaxial compressive strength (UCS). The UCS is an essential input parameter of the Hoek \& Brown failure criterion, which is used to derive the shear strength of rock masses for slope stability analysis.

In BHP Iron Ore (WAIO), during the exploration phase, trained geologists perform diamond core logging and then record in a semi-quantitative manner the intact strength of rock units along the core intervals. This record of rock strength becomes the field estimated strength (FES), and it is based on hammer blow and/or knife test. Table 1 presents the FES bins as used by WAIO and the respective strength classes as defined by International Society for Rock Mechanics (ISRM) suggested methods (1978).

Table 1 Field estimate strength bins as used in BHP

\begin{tabular}{lllccc}
\hline ISRM & ISRM term & WAIO description & $\begin{array}{c}\text { WAIO } \\
\text { acronymic }\end{array}$ & $\begin{array}{c}\text { WAIO bin } \\
\text { (MPa) }\end{array}$ & $\begin{array}{c}\text { WAIO centre of Bin } \\
\text { (MPa) }\end{array}$ \\
\hline R6 & Extremely strong & Extremely strong & ES & $>250$ & 250 \\
R5 & Very strong & Very strong & VS & $100-250$ & 175 \\
R4 & Strong & Strong & S & $50-100$ & 75 \\
R3 & Medium strong & Moderate & M & $25-50$ & 37.5 \\
R2 & Weak & Weak & W & $5-25$ & 15 \\
R1 & Very weak & Very weak & VW & $1-5$ & 3 \\
R0 & Extremely weak & Extremely weak & EW & $0.4-1$ & 0.7 \\
\hline
\end{tabular}

ISRM - International Society for Rock Mechanics; WAIO - BHP Iron Ore. 
The geologist takes UCS samples during diamond core logging. They tend to sample 'long' rock pieces, where diamond core intervals are sufficiently competent to hold an appropriated diameter-length ratio (ratio >2.5), and where bedding fabric is almost perpendicular to direction of drilling. This practical limitation of sampling and bedding orientation pre-requisites produce a UCS testing dataset but biased to non-fractured ground.

For the reasons above, the preference for slope design in WAIO is to derive the intact rock strength from the FES of diamond core logging, as it is perceived to be a more continuous sampling of ground conditions, however, the FES can inherit error caused by human bias. Note that human error is not possible to reduce by applying a more profuse data collection with classic procedures of like Point Load and Schmidt hammer field testings (these methods are only effective when the rock strength is equal or greater than R2). In the author's opinion, there is opportunity for researchers to use geophysical methods to improve the data collection of intact rock strength, this is out of scope of current paper.

There is a process for adjustment of the FES, which requires when UCS tests exist for same core interval. In this process, all UCS test results are plotted against the FES from the corresponding core interval. This permits a manual adjustment of the FES, by either downgrading or upgrading the bin class until any discrepancy to the UCS is within the acceptable range (error of \pm 1 class). This process produces an adjusted FES (Figure 1).

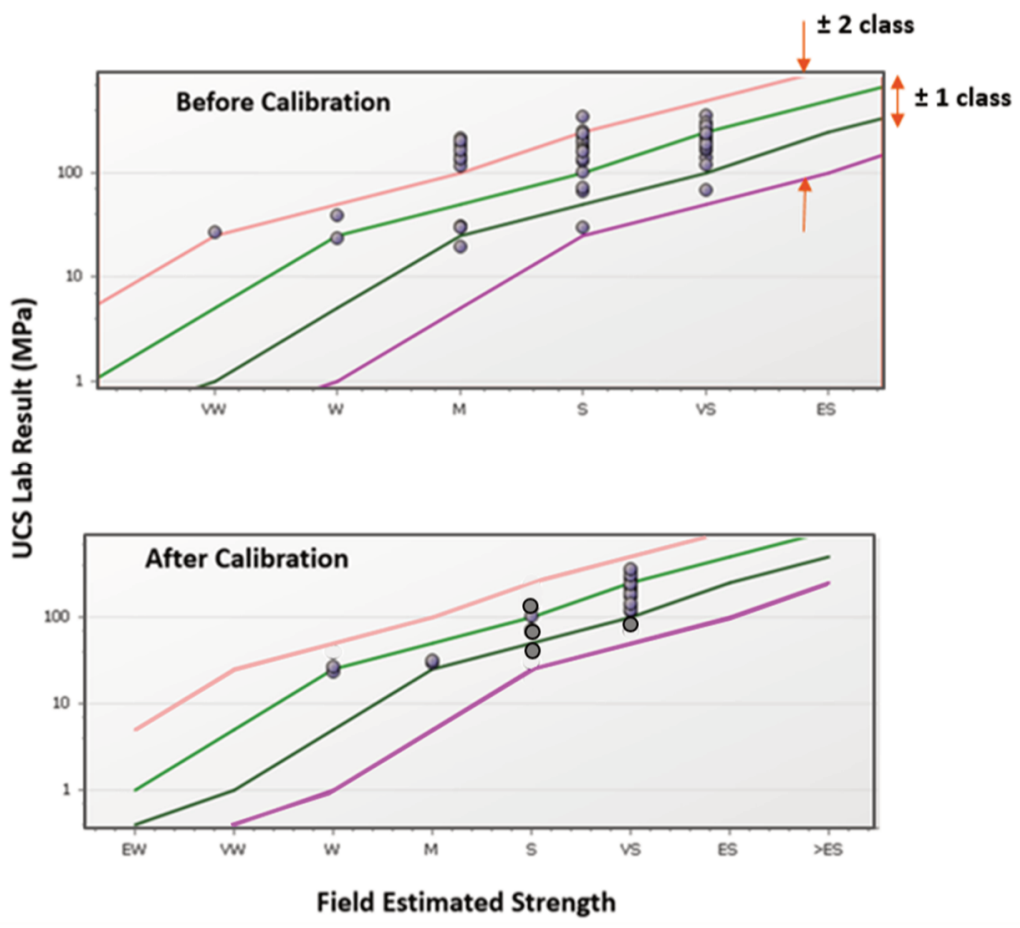

Figure 1 Representation of field estimated strength (FES) calibration: The dots in both plots represent uniaxial compressive strength (UCS) laboratory samples. FES before (top) and FES after (bottom) calibration to fit the target of within \pm 1 International Society for Rock Mechanics (ISRM) class. Note that, in both graphs, the area within the green lines represent the error band of \pm 1 class, whilst the area within the red and purple lines represent the error band of \pm 2 class

The geotechnical engineer in WAIO chooses design values for intact rock strength based on length-weighted histograms of the calibrated FES distribution for individual units. The geotechnical units follow geological units, as the geological classifications typically reflect the geotechnical properties.

The Brockman and Marra Mamba units of the Pilbara basin comprise rocks with similar lithological characteristics. Figure 2 presents the stratigraphic columns of the Marra Mamba Formation and Brockman Formation. Geotechnical units follow geological lithological units (predominantly shales and banded iron formation), further subdivided by weathering grade (oxidised or non-oxidised), and mineralisation (mineralised or non-mineralised). 


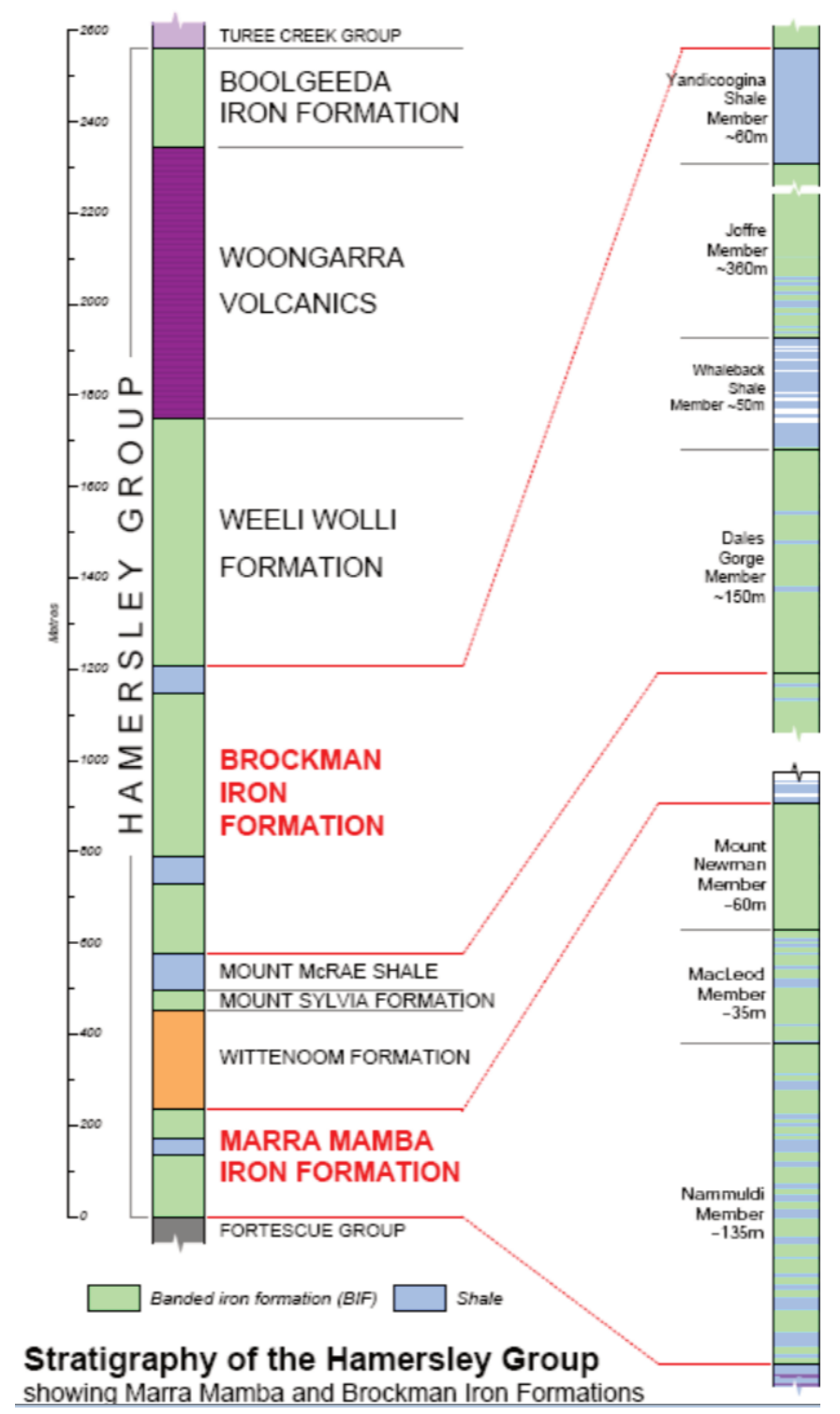

Figure 2 Simplified stratigraphy of Hamersley group after Manewell (2008)

A length-weighted approach is used to define the average, median and the standard deviation. Importantly to highlight that the calculation of the length-weighted average, as used by WAIO and previously applied by consultants, is based on the multiplication of 'centre of the bin times the length of core'.

WAIO select two design values for rock strength, a central or most realistic case and a lower case for use in sensitivity analyses. This relies on the engineering judgement considering the histogram and calculated statistics of the FES (i.e. length-weighted average, weighted median, standard deviation and first quartile). Figure 3 presents an example of histograms of calibrated FES. 


\section{Field Estimated Strength (MPa)}

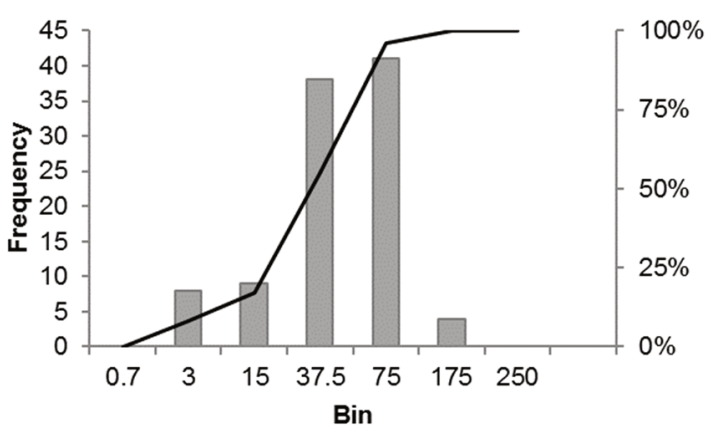

Figure 3 Typical field estimated strength (FES) histogram. Each bin has a simple frequency (bars) and cumulative frequency (line). Statistics include the weighted average, weighted median, weighted standard deviation and first quartile (25th percentile) typically

\section{Data available}

The available data for this paper includes laboratory UCS testing; and FES values from slope design reports.

Regarding the laboratory UCS testing, 504 valid results are included in this study. Tests are deemed as valid when the length-diameter ratio is $>1.9$, and the failure mode is essentially isotropic, i.e. only when failure occurs through intact matrix by either tensile splitting or shearing along a set of new shear fractures. The author recognises that this length criterion could substantially fail more rigorous definitions of validity however this has been adopted for practical purposes (a length-diameter cut-off $>2.5$ would remove $30 \%$ of the UCS results). The author judges that validating an authentic failure mode (i.e. the results did not fail on bedding) was the most important factor to qualify a valid test.

As mentioned, the histogram and calculated FES statistics are the basis of the intact rock strength estimation. In this context, statistics calculated directly from UCS laboratory tests are typically not the sole basis for estimating design strength. UCS test results only act as benchmarks to permit the calibration of the FES from its initial estimation by geologist in the field. Nevertheless, the author recognises that it is important to understand the amount of existing 'error' in the field estimate strength both 'before' and 'after' adjustment, as discussed in next section.

Regarding the FES dataset for this study, this includes the 21 geotechnical drilling investigations and design reports across the Pilbara (i.e. 24,269 metres of diamond core); in which 133 rock strength calibrations were made.

\section{Comparative study between uniaxial compressive strength and field estimated strength}

Two comparisons are possible, as follows:

- Comparing individual UCS test results against their respective FES. This represents the stage 'before calibration'.

- Comparing the FES central case against the average UCS value for each rock domain of a given report. This represents the stage of 'after calibration'.

The first comparison is possible by firstly assigning the expected bin class to each UCS result, and then comparing this against the observed bin from logging. The discrepancy between these bins defines a 'range difference' with respect to the UCS test (i.e. the true strength). Although, the histograms of 'range difference' for before calibration (see Figure 4) have almost the same centre (null difference), the spread of the data is wide for all bins. Thus, the FES is inconsistent, and it typically contains an error of \pm 2 classes. See Figure 4 for more detail. 


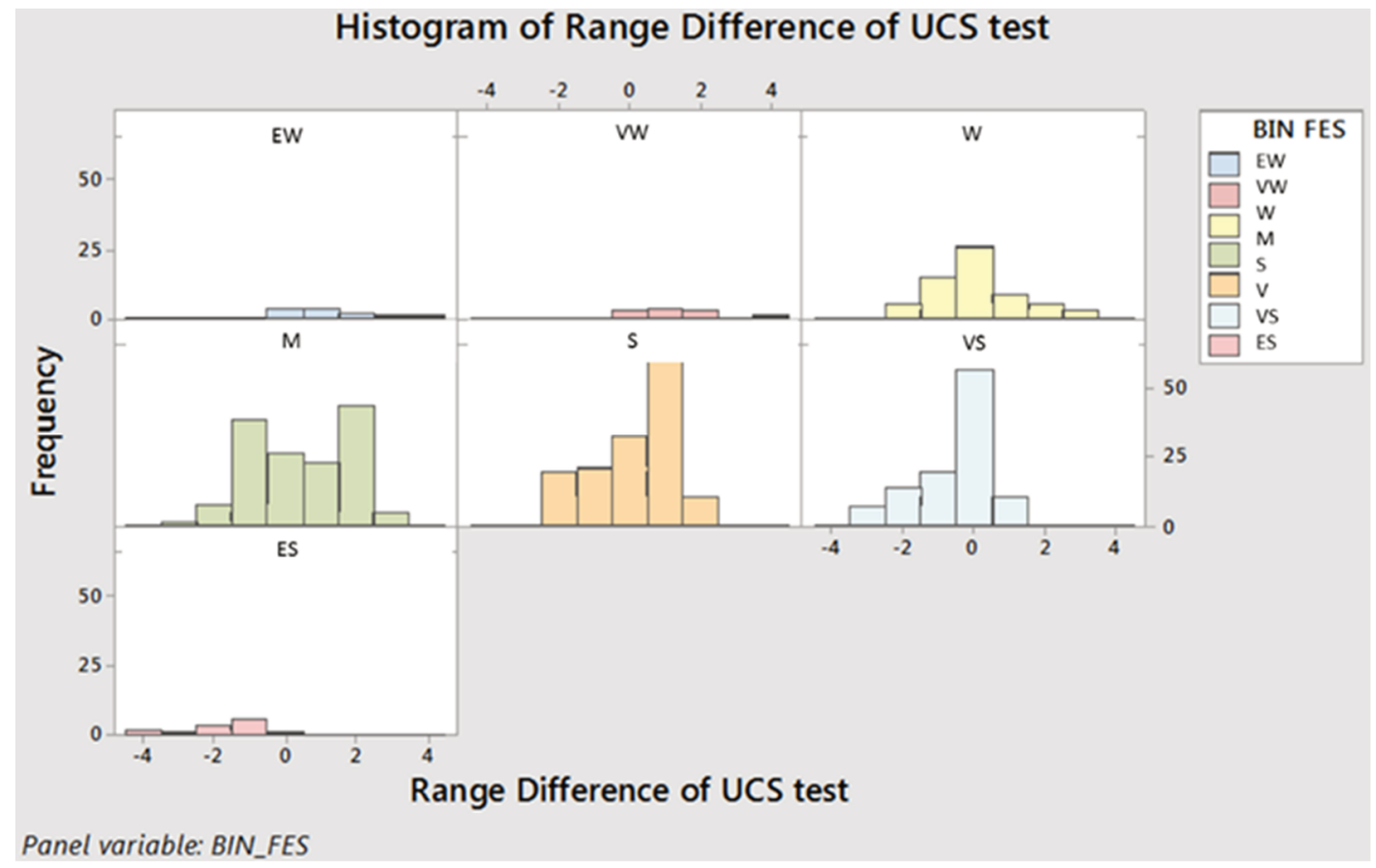

Figure 4 Histograms of the 'range difference' before calibration

After calibration, the histograms reveal an improvement on the degree of accuracy (with higher frequency of the null difference), however, there is an imprecision on the FES target of about \pm 1 class, which is considered as 'acceptable' in the current design process in WAIO (See Figure 5). Important to note that the FES central case from design reports do not include rock mass domains of Extremely Weak (EW) and Extremely Strong (ES). This absence is explained by the average ground conditions of the rock masses in the Pilbara.

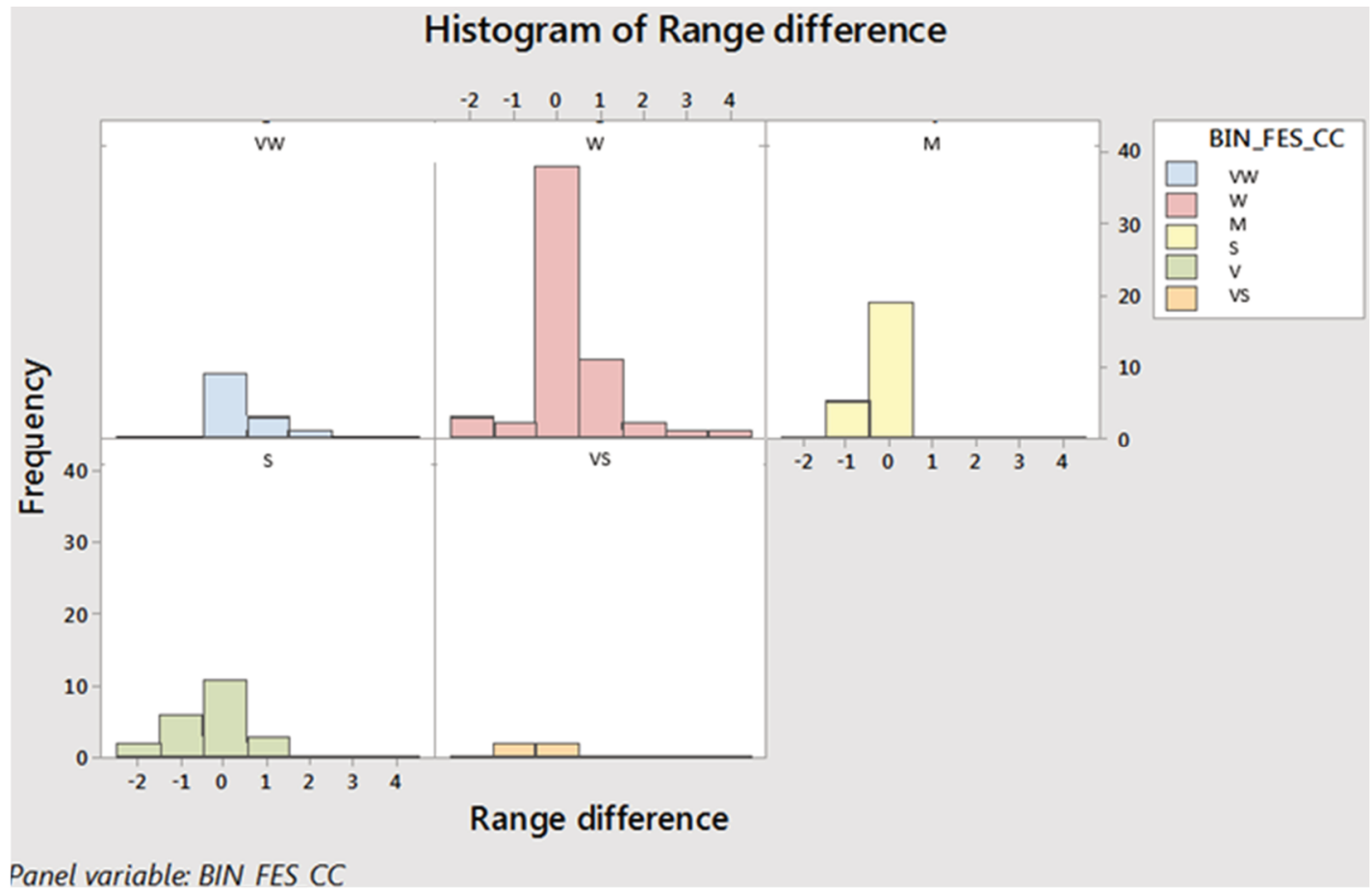

Figure 5 Histograms of the 'range difference' after calibration 


\section{$4 \quad$ Bias effects on the field estimated strength}

The author has collected the design values of FES from previous slope design reports, considering only those reports that applied calibration. These data comprises reports since 2013 to the present.

The author found that the selection of the 'central case' is not consistent enough to test the similarity of strength between rock units, in a rigorous manner. For the 'central case', the design engineers preferred the length-weighted average most of the time $(73 \%)$ rather than the weighted median. The criteria for selection of the 'lower case' was frequently consistent, commonly based on the first quartile, and very rarely based on the difference: mean value minus one standard deviation.

The author recognises that the weighted median, which is at the 50th percentile of the any data distribution, represents better the central estimate of the FES. This is judged from the following observations:

- The FES is represented using bins of different length (e.g. very weak rocks have a strength ranging within 1-5 $\mathrm{MPa}$, whilst strong rocks have a strength ranging within 50-100 $\mathrm{MPa}$ ). In such representation, the FES is almost represented as a discrete variable.

- The weighted average calculation method, as used by consultants and BHP in the last 20 years, assumes the existence of a continuous variable. In this calculation, every FES class is weighted by applying a multiplication: 'length of interval times the FES mid-point'. For example: the lengthweighted average of $100 \mathrm{~m}$, formed by $80 \mathrm{~m}$ of very weak rock and $20 \mathrm{~m}$ of strong rock, will result on a length-weighted average FES of $17.4 \mathrm{MPa}$, whilst, the weighted-median value still will be on $3 \mathrm{MPa}$. Thus, the length-weighted average calculation tends to overestimate the rock strength due to the occasional occurrence of strong samples.

- The histograms of FES, when represented as a continuous variable, reveal the existence of skewness on the distribution of FES. About $63 \%$ of FES histograms present 'positive skewed' distribution, in which, the location of the central estimates is unbalanced but in order of magnitude would tend to be weighted average $>$ weighted median $>$ modal value. Thus, the selection of length-weighted average is biased to a greater strength magnitude due to the positive skew distributions present on $F E S$, and thus it will be better to select the weighted median for slope design. Figure 6 presents a comparison between the weighted median value and the respective length-weighted average for same rock domains (all cases used for this paper).

- Conversely, the histograms of FES, when represented as a continuous variable, also reveal that $32 \%$ of FES histograms have 'negative skewed' distribution, in which, the location of the central estimates is unbalanced but in order of magnitude would tend to be weighted average $<$ weighted median < modal value. Thus, it may be appropriate to select the 'weighted average' of FES for slope design when FES presents a negative skewed distributions.

About $73 \%$ of the 'design values' for central case are based on the length-weighted average, and the remainder are length-weighted median. For the scope of the paper, the inconsistency on the selection of design values has led to the author to review the histograms of selected reports, and then to redefine the central estimate as the weighted median and the lower case as the 25th percentile for further statistical analysis, with the following intentions:

- To elevate the consistency of the FES for a fair comparison for benchmarking.

- To examine the normality of FES based on the coefficient of skewness rather than the goodness of fit testing.

- To check the need for variable transformation before performing hypothesis testing, i.e. logarithmic transformation of FES. 


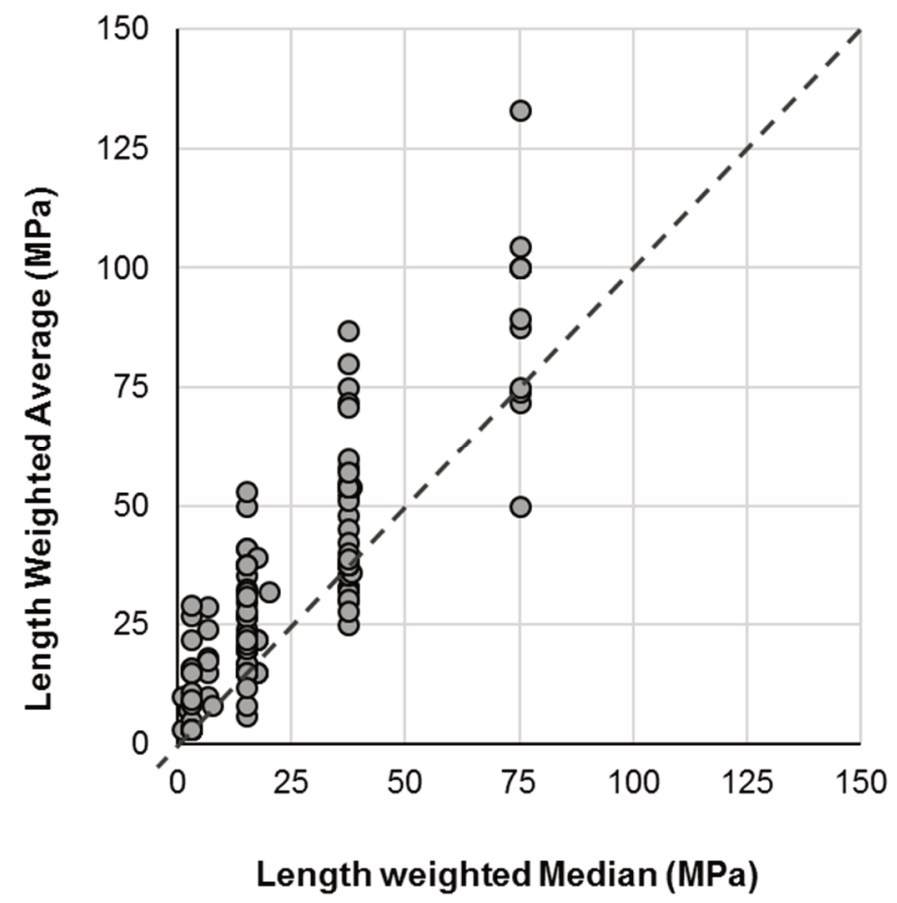

Figure 6 Comparison between the weighted-average and the weighted median values for the field estimated strength (FES)

\section{$5 \quad$ The skewness of the field estimated strength and logarithmic transformation}

Tests of normality are based on the examination of raw data (e.g. Kolmogorov-Smirnov test or similar). Most of the design reports have only provided a statistical summary (including weighted average, weighted median and standard deviation) accompanied by histograms of FES with cumulative frequency. These are without the underlying data, thus, a rigorous test of normality is difficult. To be pragmatic, the author has used the coefficient of skewness (i.e. Bowley's coefficient; https://en.wikipedia.org/wiki/Skewness) to examine if the data departs from the normal distribution. This coefficient is defined as following:

$$
S k=\frac{\left(Q_{1}+Q_{3}\right)-2 * Q_{2}}{\left(Q_{3}-Q_{1}\right)}
$$

where:

$$
\begin{aligned}
& \mathrm{Q} 1=25 \text { th percentile. } \\
& \mathrm{Q} 2=50 \text { th percentile. } \\
& \mathrm{Q} 3=75 \text { th percentile. }
\end{aligned}
$$

The possible values for this coefficient are within the range -1 to 1 , and they can serve to inform:

- When $\mathrm{Sk}=0$, data is normally distributed, meaning that mean $=$ median $=$ mode

- $\mathrm{Sk}>0$, data is positive skewed, thus: mean $>$ median $>$ mode.

- $\mathrm{Sk}<0$, data is negative skewed, whilst: mean $<$ median $<$ mode.

Since, the FES is typically positive skewed, it is required to transform the variable to a logarithmic form. This was conducted using the logarithm on base $e=2.71$. This transformation is required to ensure that the variable used for hypothesis testing is normally distributed (McKillup \& Darby Dyar 2010). 
It is important to note that the proportion of data limited by the quartiles remain unchanged after logarithmic transformation. Thus, the author proposed that it is possible to estimate the standard deviation of the transformed variable, based on the quartiles and the standardised normal distribution, as follows:

$$
S D=\left(\frac{\operatorname{Ln} Q_{2}-\operatorname{Ln} Q_{1}}{Z_{0.5}-Z_{0.25}}\right)
$$

From the above, the Author proposes to use the standard deviation to calculate the variance of the 'logarithmic FES' using the expression: Variance $=$ SD $^{2}$ (Levine et al. 2013). The logarithmic weighted median and the variance are both utilised to perform Analysis of Variance (ANOVA) analysis, Tukey-Kramer procedure and Student hypothesis testing to detect the similarity of populations.

Figure 7 presents the cumulative distribution of the skewness coefficient for the FES. Based on the skewness coefficient, it is possible to establish that $63 \%$ of the data has a 'positive' skew, whilst $32 \%$ of data presents 'negative' skew and only $5 \%$ of samples present a normal distribution. The natural values of FES are transformed into their logarithmic form to increase the normality of data, which is required for hypothesis testing (McKillup \& Darby Dyar 2010). This transformation of data will still leave negative skewness in $5 \%$ of the data (i.e. coefficient skewness $<-0.5$ ), which is not considered material.

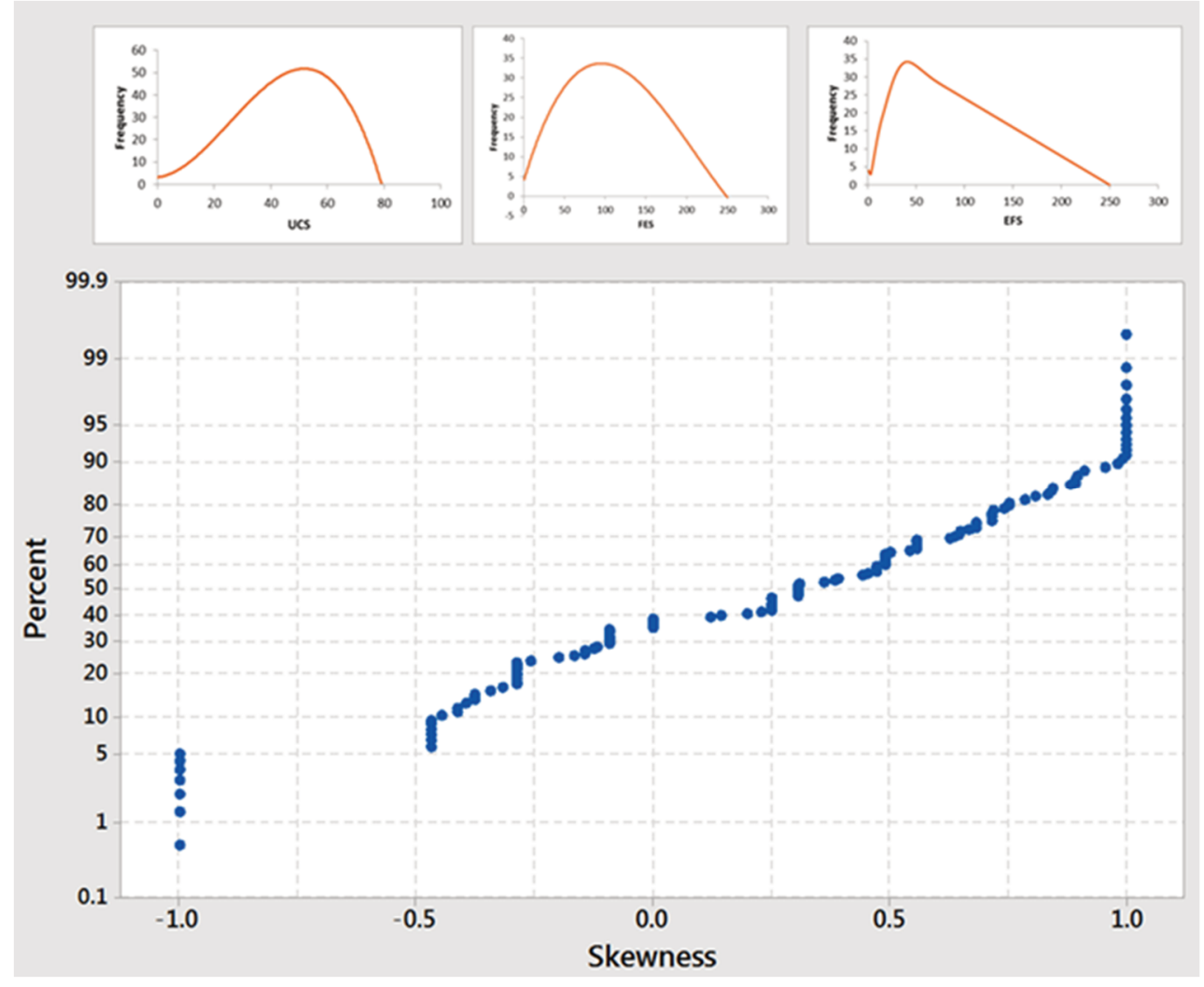

Figure 7 Cumulative distribution of the skewness coefficient for FES (all rock units)

\section{$6 \quad$ Hypothesis testing and typical values}

The following assumptions are made before performing hypothesis testing:

- The weighted median is the best representation of the central case of the field-estimated strength. Whilst the lower case is based on the first quartile.

- By observation of the skewness coefficient, the majority of the field-estimated strength is not normally distributed but positively skewed. For pragmatism, it is assumed that the skewness of the FES obeys a lognormal distribution. Thus, the ordinary quartiles are transformed to logarithmic value to return a reasonable approximation of a normal distribution (transformation is based on the exponential $\mathrm{e}=\mathbf{2 . 7 1 8 2 8}$ ). 
- The logarithmic transformation does not affect the interquartile range (difference between the weighted median and the first-quartile). Thus, an equivalent standard deviation is calculated post-logarithmic transformation, which permits the use of ANOVA (Maldonado \& Haile 2015). The main factors controlling the similarity of FES across deposits are linked to the geological setting. Then the data of FES is segregated by stratigraphy, lithology type and weathering grades.

- The 'weathering' is simply defined as weathered or fresh. This is aligned with the modelling resolution used for slope stability analysis, where the materials above the base of completed oxidation (BOCO) are considered weathered, whilst below BOCO are considered as fresh rocks.

- In the present study, sample size is a synonym of 'drilling metres'. However, the requirement for minimum sample size is lifted up from five entries (typical on statistical literature) to 30 entries. This obeys to the scale of stratigraphic units, which can reach a thickness of $30 \mathrm{~m}$. Thus, sample sizes $\geq 30 \mathrm{~m}$ are considered as representative of the rock units, and suitable for reliable data comparison, whilst sample sizes $<30 \mathrm{~m}$, are considered as having low confidence.

The assumptions above permit hypothesis testing based on the following approach:

- For multiple comparisons: ANOVA, Analysis of similarity of means (Tuckey-Kramer comparison).

- For comparisons of two samples: Hypothesis testing by F-test (equal variance) and T-test (equal means).

All the above methods used a confidence interval of $95 \%$ for acceptance of similarity between populations. In this case, the $p$-value should be greater than 5\% (T-test and Tuckey-Kramer procedure); whilst for equal variance the $p$-value should be greater than $2.5 \%$ (ANOVA and F-test).

The sample for this report includes the calibrated FES from slope design reports across multiple drilling and design project in the Pilbara, which include the nine mine sites. This sample sums a total of $24,269 \mathrm{~m}$ of diamond core. Table 2 below presents the distribution of samples within stratigraphical member, lithology type and per each deposit.

Table 2 Sample distribution per stratigraphical unit and per deposit for weathered materials

\begin{tabular}{|c|c|c|c|c|c|c|c|c|c|c|}
\hline \multirow{2}{*}{ Formation } & \multirow{2}{*}{ Member } & \multicolumn{9}{|c|}{ Deposit } \\
\hline & & Lithology & ER & $\mathbf{H}$ & NF & $\mathbf{P}$ & SF & SJ & WB & Wh \\
\hline Weeli Wolli & $\begin{array}{l}\text { Weeli Wolli } \\
\text { Dolerite }\end{array}$ & Dolerite & 118 & & & 267 & & & & \\
\hline \multirow[t]{4}{*}{ Brockman } & Yandicoogina Shale & Shale & 162 & 306 & & 171 & & & & \\
\hline & Joffre* & BIF & 60 & 310 & & 1,056 & & & 523 & 82 \\
\hline & $\begin{array}{l}\text { Mt Whaleback } \\
\text { Shale }\end{array}$ & Shale & 84 & & & 325 & & & 194 & \\
\hline & Dales Gorge* & BIF & 1,347 & & & 1,708 & & & 1,493 & 870 \\
\hline $\begin{array}{l}\text { Mount } \\
\text { McRae }\end{array}$ & $\begin{array}{l}\text { Mount McRae } \\
\text { Shale }\end{array}$ & Shale & 304 & & & 422 & & & 385 & \\
\hline Mt Sylvia & Mt Sylvia & Shale & & & & 128 & & & 190 & 292 \\
\hline \multirow[t]{2}{*}{ Wittenoom } & Paraburdoo & Dolomite & & 51 & 76 & & & & 301 & \\
\hline & West Angela & BIF/Shale & & 201 & 20 & & 314 & 1,643 & & \\
\hline Marra & Mount Newman* & BIF & 253 & & 811 & & 611 & 1,985 & 549 & \\
\hline \multirow[t]{2}{*}{ Mamba } & MacLeod & Interbedded & & & 1,018 & & & 1,045 & 1,304 & \\
\hline & Nammuldi* & BIF & & & 18 & & & 1,004 & 158 & \\
\hline Jeerinah & Jeerinah & Shale & & & & & & 641 & & \\
\hline
\end{tabular}

ER = Eastern Ridge, $\mathrm{H}=$ Homestead, NF = North Flank, $\mathrm{P}=$ Packsaddle, SF = South Flank, SJ = South Jimblebar, WB = whaleback, Wh = Whelarra

Units with $(*)$ includes interbedded shale and banded iron formation (BIF) materials. Marillana Formation, Bee Gorge Formation and Weeli Wolli Iron Formation are not included in the dataset. 
As expected by the author, the sample distribution is uneven, particularly with respect to weathering and distribution across deposits. The dataset for Fresh or Slightly Weathered materials represents about $6 \%$ of the overall data, whilst, $94 \%$ of the dataset includes Moderate, Highly and Extremely Weathered materials (above BOCO). Thus, the paper only presents the results of hypothesis testing for 'weathered' rock units, table 2 below summarised sample distribution per deposit, stratigraphy and lithology type for weathered materials only.

The results of hypothesis testing are summarised in Table 3 . It is important to recognise that the similarity testing has revealed some particular findings within the Brockman column: the Dales Gorge member passed the test of similarity when dataset is split by lithology type: a shale dominant group (D1 and D3 units) and a BIF dominant (D2 and D4 units); Likewise, the Joffre Member should be split by lithology, resulting in a group formed by $\mathrm{J} 1, \mathrm{~J} 3$ and $\mathrm{J} 5$ and group formed by $\mathrm{J} 2, \mathrm{~J} 4$ and $\mathrm{J} 6$. However, it is important to mention that from all these units in Joffre, J4 is the least logged $(131 \mathrm{~m})$, which involves some uncertainty when defining typical values. Note that $\mathrm{J} 4$ is a very thin unit with 6 to $9 \mathrm{~m}$ of thickness.

Weathered dolerite dykes, which are part of the Weeli Wolli Formation, did not pass the test of similarity between projects (deposits Eastern Ridge and Packsaddle). Perhaps, the natural variations on the composition of dolerite dykes across multiple sites may explain for this heterogeneity in strength, which is also reported in other projects from north of the Pilbara.

Some stratigraphical units had insufficient sample size for reliable hypothesis testing (i.e. WA1, Joffre J4). In some cases, there is bias towards one project, specifically, mineralised Joffre $(80 \%$ from Packsaddle deposit), mineralised West Angela 'WA1' (75\% from North Flank deposit) and dolomite units from Wittenoom Member (where only two projects were tested).

Table 3 Summary of the hypothesis testing results

\begin{tabular}{|c|c|c|c|c|c|c|c|}
\hline Formation & $\begin{array}{l}\text { Lithology } \\
\text { type }\end{array}$ & $\begin{array}{c}\text { Stratigraphical } \\
\text { unit }\end{array}$ & $\begin{array}{c}\text { Sample } \\
\text { size } \\
\text { (metres) }\end{array}$ & $\begin{array}{c}\text { F-test } \\
\text { p-value } \\
>0.025\end{array}$ & $\begin{array}{c}\text { T-test } \\
\text { p-value } \\
>0.05\end{array}$ & $\begin{array}{c}\text { ANOVA } \\
\text { p-value } \\
>0.025 \\
\end{array}$ & $\begin{array}{c}\text { Similar } \\
\text { population }\end{array}$ \\
\hline Weeli Wolli & $\mathrm{D}$ & & 385 & 0.000 & 0.000 & $\mathrm{n} / \mathrm{a}$ & No \\
\hline Yandicogina & SHL & & 610 & $\mathrm{n} / \mathrm{a}$ & $\mathrm{n} / \mathrm{a}$ & 0.990 & Yes \\
\hline \multirow[t]{3}{*}{ Joffre } & BIF-U* & $\mathrm{J} 1, \mathrm{~J} 3, \mathrm{~J} 5$ & 847 & $\mathrm{n} / \mathrm{a}$ & $\mathrm{n} / \mathrm{a}$ & 0.990 & Yes \\
\hline & BIF-U** & $\mathrm{J} 2, \mathrm{~J} 4, \mathrm{~J} 6$ & 728 & $\mathrm{n} / \mathrm{a}$ & $\mathrm{n} / \mathrm{a}$ & 0.990 & Yes \\
\hline & BIF-M & & 263 & $\mathrm{n} / \mathrm{a}$ & $\mathrm{n} / \mathrm{a}$ & 0.026 & Yes \\
\hline Whaleback & $\mathrm{SHL}$ & & 603 & $\mathrm{n} / \mathrm{a}$ & $\mathrm{n} / \mathrm{a}$ & 0.990 & Yes \\
\hline \multirow[t]{3}{*}{ Dales Gorge } & BIF-M & All & 1,372 & $\mathrm{n} / \mathrm{a}$ & $\mathrm{n} / \mathrm{a}$ & 0.060 & Yes \\
\hline & BIF-U & $\mathrm{D} 2, \mathrm{D} 4$ & 1,416 & $\mathrm{n} / \mathrm{a}$ & $\mathrm{n} / \mathrm{a}$ & 0.99 & Yes \\
\hline & BIF-U* & D1, D3 & 2,162 & $\mathrm{n} / \mathrm{a}$ & $\mathrm{n} / \mathrm{a}$ & 0.99 & Yes \\
\hline McRae & $\mathrm{SHL}$ & all & 726 & $\mathrm{n} / \mathrm{a}$ & $\mathrm{n} / \mathrm{a}$ & 0.99 & Yes \\
\hline Sylvia & SHL & $\mathrm{S} 1-\mathrm{S} 6$ & 551 & $\mathrm{n} / \mathrm{a}$ & $\mathrm{n} / \mathrm{a}$ & 0.99 & Yes \\
\hline Wittenoom & DOL & & 127 & 0.990 & 0.395 & $\mathrm{n} / \mathrm{a}$ & Yes \\
\hline \multirow[t]{2}{*}{ West Angelas } & BIF-M & WA1 & 153 & $\mathrm{n} / \mathrm{a}$ & $\mathrm{n} / \mathrm{a}$ & 0.03 & Yes \\
\hline & SHL & WA2 & 2,025 & $\mathrm{n} / \mathrm{a}$ & $\mathrm{n} / \mathrm{a}$ & 0.99 & Yes \\
\hline \multirow[t]{2}{*}{ Newman } & BIF-M & & 761 & 0.990 & 0.399 & $\mathrm{n} / \mathrm{a}$ & Yes \\
\hline & BIF-U & & 939 & $\mathrm{n} / \mathrm{a}$ & $\mathrm{n} / \mathrm{a}$ & 0.99 & Yes \\
\hline McLeod & BIF-U* & & 3,362 & $\mathrm{n} / \mathrm{a}$ & $\mathrm{n} / \mathrm{a}$ & 0.99 & Yes \\
\hline Nammuldi & BIF-U & & 205 & $\mathrm{n} / \mathrm{a}$ & $\mathrm{n} / \mathrm{a}$ & 0.99 & Yes \\
\hline
\end{tabular}

$\mathrm{D}=$ dolerite $\mathrm{SHL}=$ shale, $\mathrm{BIF}-\mathrm{U}=$ non-mineralised $\mathrm{BIF}, \mathrm{BIF}-\mathrm{M}=$ mineralised $\mathrm{BIF}, \mathrm{DOL}=$ dolomite, $\mathrm{BIF}-\mathrm{U}^{*}=$ non-mineralised $\mathrm{BIF}$ with interbedded shale, $\mathrm{BIF-U**}=$ interbedded shale.

The similarity testing has the intention of defining 'typical' strength values where similarity is proven. The precision around the typical value can be measured by the Precision Index when the variable in study is 
normally distributed. Thus, the application on Precision Index has been applied to the log-transformed FES values post hypothesis testing. This approach is used to inform on the design level of study.

Based on the results of the similarity testing, typical values are defined and presented in Table 4. Typical values are selected based on the median of each subset. For WAIO, the adoption of standard strength values from Table 4 for slope design appears to be sufficient as the Precision Index in the logarithmic FES is high, and sufficient to recommend 'typical' bin values for detail design level (all units here having high level of confidence, and high Precision Index). Provisional design level of study has either limited datasets or low Precision Index).

Table 4 Typical values for rock strength of Archean units of the Pilbara

\begin{tabular}{|c|c|c|c|c|c|}
\hline Units & Lithology & Subdivision & $\begin{array}{l}\text { Most likely } \\
\text { weighted } \\
\text { median (FES) }\end{array}$ & $\begin{array}{c}\text { 25th } \\
\text { percentile } \\
\text { (FES) }\end{array}$ & Design level \\
\hline \multirow[t]{2}{*}{ Yandicogina } & SHL & & 3.0 & 1.0 & Detailed \\
\hline & BIF-U/INT & $\mathrm{J} 1, \mathrm{~J} 3, \mathrm{~J} 5$ & 15.0 & 3.0 & Detailed \\
\hline \multirow[t]{2}{*}{ Joffre } & BIF-U & $\mathrm{J} 2, \mathrm{~J} 4, \mathrm{~J} 6$ & 37.5 & 15.0 & Detailed \\
\hline & BIF-M & All & 15.0 & 3.0 & Provisional \\
\hline \multirow[t]{2}{*}{ Whaleback } & SHL & & 15.0 & 3.0 & Detailed \\
\hline & BIF-M & All & 15.0 & 5.0 & Detailed \\
\hline \multirow[t]{2}{*}{ Dales Gorge } & BIF-U & D2, D4 & 37.5 & 15.0 & Detailed \\
\hline & BIF-U/INT & D1, D3 & 15.0 & 5.0 & Detailed \\
\hline McRae & SHL & & 3.0 & 1.0 & Detailed \\
\hline Sylvia & SHL & & 15.0 & 3.0 & Detailed \\
\hline Wittenoom & DOL & & 15.0 & 3.0 & Provisional \\
\hline \multirow{2}{*}{ West Angels } & BIF-M & WA1 & 15.0 & 3.0 & Provisional \\
\hline & SHL & WA2 & 3.0 & 1.0 & Provisional \\
\hline \multirow{2}{*}{ Newman } & BIF-M & & 3.0 & 1.0 & Detailed \\
\hline & BIF-U & & 37.5 & 15.0 & Detailed \\
\hline McLeod & BIF-U/INT & & 37.5 & 15.0 & Detailed \\
\hline Nammuldi & BIF-U & & 37.5 & 15.0 & Provisional \\
\hline
\end{tabular}

$\mathrm{SHL}=$ shale, $\mathrm{BIF}-\mathrm{U}=$ non-mineralised $\mathrm{BIF}, \mathrm{INT}=$ Interbedded, $\mathrm{BIF}-\mathrm{M}=$ mineralised $\mathrm{BIF}, \mathrm{DOL}=$ dolomite

Table 4 excludes some rock units, which have limited drilling data. Nonetheless, previous field experience (i.e. during face mapping in WAIO) permits the author to tentatively summarise the most likely FES typical values for some other units not included in Table 4. However, it is advisable that below values are only used for conceptual level of studies and thus with caution, as there is no hypothesis testing to test similarity across WAIO (i.e. ground conditions are likely to be different that the author's experience).

- Hard cap. Experience indicates this lithology as being consistently strong, with FES ranging within 50-100 MPa. Thus, in case of absence of drilling data, it is advisable to use $75 \mathrm{MPa}$ and $50 \mathrm{MPa}$ for representation of central estimate and lower case of the FES strength.

- Dales Gorge (i.e. D3 unit when BIF-U is dominant). The FES increases slightly with central estimate towards the upper end on Weak rock, $25 \mathrm{MPa}$ and whilst the lower case approaches the mid-point of weak rock, $15 \mathrm{MPa}$.

- Mt Sylvia - Bruno's band or the S5 cherty units. Experience reveals these units are Moderate Strong rocks (FES ranging within 25 to $50 \mathrm{MPa}$ ). In absence of drilling data, it is advisable to use $37.5 \mathrm{MPa}$ and $25 \mathrm{MPa}$ for representation of central estimate and lower case of the FES strength. 
- Newman and McLeod shales units. These rocks present anisotropic strength, where bedding shear strength controls their behaviour. Nevertheless, the FES for shale units is approximated by a central estimate $=3 \mathrm{MPa}$ and a lower case $=1 \mathrm{MPa}$.

- Welli Wolli BIF. Experience indicates this lithology as being consistently moderate strong, with FES ranging within 25 to $50 \mathrm{MPa}$. Thus, in absence of drilling data, it is advisable to use $37.5 \mathrm{MPa}$ and $25 \mathrm{MPa}$ for representation of central estimate and lower case of the FES strength.

\section{$7 \quad$ Recommendations}

- The use of skewness factor permits a rapid evaluation of normality with limited datasets. Its use is advisable.

- The use of hypothesis testing on logarithmic transformed data appears to be a good approach to compare naturally logarithmic datasets like FES variable.

- The typical values from FES are sufficient to define similar bin values, where data is recorded in binning manner.

- This paper presents methods to increase the confidence of field estimate of intact rock strength and is of interest to the rock mechanics community. The approach of calibration of FES, logarithmic transformation and hypothesis testing appears to be a plausible methodology for replication elsewhere in the mining industry.

\section{Acknowledgement}

The authors of this paper desire to thank to BHP geotechnical engineering team for supporting this work. In addition, the author thanks to Ted Brown as the external review of the project in 2017. Similarly, I desire to express my gratitude to Andy Haile and Ken Mercer for encouraging the PhD work since November 2015.

\section{References}

Hoek 2000, Practical Rock Engineering, Short course notes, Vancouver, Canada.

International Society for Rock Mechanics 1978, 'Suggested methods for the quantitative description of the discontinuities in rock masses', Journal of Rock Mechanics and Mining and Geomechanics, vol. 15, pp. 319-368.

Levine, D 2013, Statistics for managers, Pearson Publication, Melbourne.

Maldonado, A \& Haile, A 2015, 'Application of ANOVA and Tuckey-Cramer, statistical analysis to determine similarity of rock mass strength properties across Banded Iron Formations of the Pilbara region in Western Australia', Proceedings of the 2015 International Symposium on Slope Stability in Open Pit Mining and Civil Engineering, The Southern African Institute of Mining and Metallurgy, Johannesburg.

Manewell 2008, The Hydrogeology and Hydrochemistry of the Mt. Tom Price Mine, Pilbara, Western Australia - A Groundwater Flow Model, Thesis, Engineering Geology University of Canterbury.

McKillup, S \& Darby Dyar, M 2010, Geostatistics Explained: An Introductory Guide for Earth Scientists, Cambridge University Press. 